\title{
Entspannt euch!
}

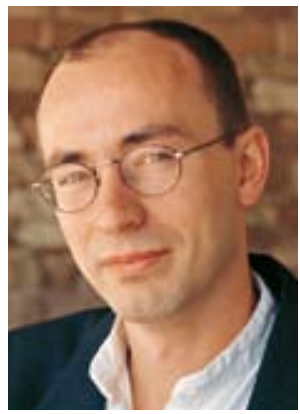

Dr. med. Dieter Schmid, Redaktionsleitung

$\mathrm{Na}$, wie viele Braunülen haben Sie schon gelegt? Und wie oft haben Sie intubiert? Sicher haben Sie doch wenigstens schon mal eine Platzwunde genäht, oder? ... Solche Fragen sind Nadelstiche ins Fleisch vieler junger Mediziner. Zwar empfinden Medizinstudenten laut einer Befragung des Medizinischen Fakultätentages (MFT) das Studium heute als um $30 \%$ praxisrelevanter als vor zehn Jahren. Die meisten sehen, was ihre praktische Ausbildung anbelangt, aber immer noch ein gewaltiges Defizit. In unserem Artikel „Praxis verzweifelt gesucht“ auf $\mathbf{S} .12$ geben wir Ihnen Tipps, wie Sie diesem Mangel begegnen können. Gleichzeitig macht unser Autor aber auch eines deutlich: Handwerkliche Fertigkeiten sind wichtig - beim Klinikeinstieg sind sie aber beileibe nicht das Wichtigste.

In Bielefeld ereignete sich kürzlich ein schrecklicher Zwischenfall, der anschaulich vor Augen führt, worauf es in der Ausbildung junger Ärzte tatsächlich ankommt: Ein PJler spritzte einem leukämiekranken Baby einen antibiotischen Saft, der für den oralen Gebrauch bestimmt gewesen wäre, in die Vene. Alle intensivmedizinischen Maßnahmen halfen nichts - der bereits schwer kranke Junge starb kurze Zeit später. Ein Leben ist zerstört, womöglich auch die Zukunft des jungen Mediziners. Mangelte es in diesem Fall an handwerklichen Fertigkeiten? Den Beipackzettel eines Medikaments zu lesen ist keine große Kunst. Nein, ich könnte mir vorstellen, dass der Kern des Problems hier ein anderer war: Junge deutsche Mediziner strotzen vor theoretischen Kenntnissen und haben zumeist auch ausreichende praktische Fertigkeiten. Ihr Problem ist: Sobald sie beginnen, eigenverantwortlich zu arbeiten, tun sie sich schwer, die Orientierung zu behalten: Worauf kommt es wirklich an? Wo muss ich aufpassen? Wann kann ich cool bleiben? Gefährliche Situationen werden zu spät erkannt, oder - was noch häufiger ist - der junge Arzt geht mit einem inwendig blinkenden Warnlicht durch die Gänge, weil er überall potenzielle Fehler wittert. Eine von uns interviewte Ärztin spricht davon, dass ihr in den ersten Wochen jede verordnete Ibuprofen noch stundenlang durch den Kopf gespukt sei. Ist dieser „Sprung ins kalte Wasser“ obligat? Muss man verantwortliches Handeln zwingend nach dem gefährlichen „Lernen-aus-Fehlern-Prinzip“ lernen? Nein! Man kann es auch beibringen. Das funktioniert dann, wenn die ausbildenden Kollegen ihre Aufgabe nicht nur im Sinn einer Krisenintervention ausüben, sondern eine engmaschige Supervision pflegen, die Fragen zulässt und dem jungen Arzt zwar Verantwortung überträgt, gleichzeitig aber die Gewissheit gibt, dass eine zweite Person über das eigene Tun wacht.

Meine Empfehlung: Wenn Sie Praxisdefizite fühlen, steuern Sie moderat gegen - machen Sie sich deshalb aber keinen Stress. Und wenn Sie Ihre erste Stelle suchen, halten Sie inne - und wählen Sie eine Ausbildungsstätte, bei der die beschriebenen Anforderungen weitestgehend erfüllt sind. Die Freiheit dazu haben Sie.

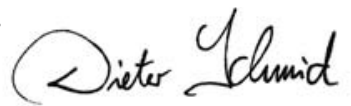

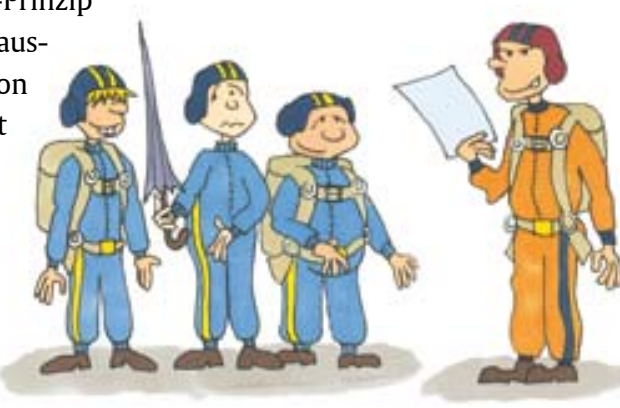

„So, wie ich sehe, seid ihr ja perfekt gerüstet für unseren Fallschirmspringerkurs. Wer von euch war jetzt noch mal der Mediziner ... ?“

ONLINE-UMFRAGE

\section{Mehr Praxis à la francais?}

In Deutschland wird seit Jahren daran laboriert, die praktische Ausbildung der deutschen Medizinstudenten zu verbessern. Wer im Aachener Modellstudiengang studiert, hat z. B. schon ab dem dritten Semester Untersuchungskurse. Ab dem 8. Semester kommen dann die Blockpraktika, in denen die Studenten vier Tage in der Woche ein Semester lang eine Station besuchen. Doch ist das der Weisheit letzter Schluss? In Frankreich sind die Studenten deutlich enger in den Arbeitsalltag involviert. Ab dem 3. Jahr arbeiten sie halbtags als „Externes“ auf einer Station mit, wo sie fixe Verantwortlichkeiten haben und dafür auch ein geringes Entgelt (ca. $200 € /$ Monat) kassieren. Welches Modell finden Sie besser?

\section{Würden Sie es begrüßen, wenn Sie im Interesse einer besseren praktischen Ausbildung wie in Frankreich regelmäßig und verpflichtend halbtags auf Station mitarbeiten müssten?}

Stellen Sie sich dieser kniffligen Frage unter: www.thieme.de/viamedici/aktuelles/aktion/ miniumfrage5-11.html
- Ergebnis der Umfrage in Via medici 4.11: Wir fragten, welche Neuregelung Sie für sinnvoll halten, um den Mangel an Spenderorganen in Deutschland zu beheben. Mit 51\% lag die Widerspruchslösung, bei der Organe bei fehlendem Patienten-Veto entommen werden können, eine Nasenlänge vor der von der Politik favorisierten Entscheidungslösung (47\%). Einige Teilnehmer kommentierten allerdings, man sollte auf die Organe besser verzichten, bevor man Menschen aufgrund der Widerspruchslösung Organe gegen deren Willen entnimmt. Mehr Kommentare unter: .../aktuelles/aktion/miniumfrage4-11.html 